\title{
Editorial conventions
}

The Bibliography of the International Arthurian Society (BIAS) lists all scholarly books and articles directly concerned with the matière de Bretagne. Subjects which are only indirectly concerned with it, such as the origins of courtly love, are deliberately excluded. Also excluded are popular works, general surveys found in histories of literature and most studies which deal with the Arthurian tradition after the sixteenth century. Within these limits, the Bibliography aims to include all books, reviews and articles published in the year preceding its appearance, an exception being made for earlier studies which have been omitted inadvertently.

Each national branch of the Arthurian Society is responsible for its own section of the Bibliography. Each section is divided into four parts: I. Texts, Translations and Adaptations; II. Critical and Historical Studies; III. Reviews; IV. Reprints; V. Doctoral Dissertations/Higher Degree Theses. The contents of each section are arranged in the alphabetical order of authors' names. As often as possible a brief, objective account is given of the contents of each study listed in the Bibliography. For practical purposes, as well as to conform to a decision taken at the Second Triennial Arthurian Congress, these digests are given in English, French or German. Each section of the Bibliography is printed in alphabetical order according to nationality. The first publication listed for each year is given the number one; the rest follows in numerical order down to the end of the Bibliography. Any reference to the Bibliography should therefore include the number of the Bulletin, the year and the number of the individual publication, e. g. BBIAS, I, 1949, 20. At the end of the Bibliography are printed two indexes, one of authors and one of subject-matter. The indexes are prepared by the bibliographers of the national branches. The style of the items differs from preceding volumes due to technical reasons. 